\title{
Short-term Effect of Radical Hysterectomy with or without Adjuvant Radiation Therapy on Urodynamic Parameters in Patients with Uterine Cervical Cancer
}

\author{
Jin Kyu Oh, Min Soo Choo ${ }^{1}$, Joongyub Lee ${ }^{2}$, Noh-Hyun Park ${ }^{3}$, Seung-June $\mathrm{Oh}^{1}$ \\ Department of Urology, Gachon University Gil Hospital, Incheon; ${ }^{1}$ Department of Urology, Seoul National University Hospital, Seoul; ${ }^{2}$ Medical Research \\ Collaborating Center, Seoul National University Hospital, Seoul; ${ }^{3}$ Department of Obstetrics and Gynecology, Seoul National University Hospital, Seoul, Korea
}

\begin{abstract}
Purpose: Lower urinary tract dysfunction is the most common complication after radical pelvic surgery. The aims of this study were to assess the effect of radical hysterectomy $(\mathrm{RH})$ on the storage function of the lower urinary tract and to evaluate the impact of radiation therapy (RT) on postoperative urodynamic parameters.

Methods: This was a retrospective review of preoperative and postoperative urodynamic variables, which were prospectively collected. All women from 2006 to 2008, who underwent RH for uterine cervical cancer with a stage of 1A to 2B with or without adjuvant RT were enrolled. All patients were divided into two groups: group 1, without RT, and group 2, with adjuvant RT. Urodynamic studies were performed before, 10 days after, and 6 months after RH.

Results: A total of 42 patients with a mean ( \pm standard error) age of $51.9( \pm 12.3)$ years were analyzed. There were no significant differences in age, body mass index or clinical stage between the two groups. On the 10th postoperative day, all parameters were decreased except postvoid residual volume. In comparison with group $2(n=14)$, group $1(n=28)$ showed a significant increase in bladder compliance. At 6 months postoperatively, bladder compliance in group 1 had increased four times or more compared with that on postoperative 10 days. However, it had increased only 2.5 times in group 2 at the same time point $(\mathrm{P}<0.001)$.

Conclusions: The results of our study suggest that adjuvant RT after RH might result in a deterioration of bladder compliance. It is highly suggested that practitioners pay attention to low bladder compliance, especially in patients who have adjuvant RT after RH.
\end{abstract}

Keywords: Urinary bladder; Radiotherapy; Urodynamics

\section{INTRODUCTION}

Uterine cervical cancer is a common cancer among women and is one of the leading causes of cancer-related deaths in females [1]. Radical hysterectomy (RH) is the treatment of choice in patients with early-stage uterine cervical cancer. A few studies have reported that transient changes in bladder function are common after RH [2-4]. Chen et al. [3] suggested that the post-hysterectomy changes in urinary tract function may be related to the partial denervation of autonomic nerves.

In high-risk patients who have positive pelvic lymph nodes or microscopic parametrial involvement or positive margins, adjuvant radiation therapy (RT) is a feasible option for survival. Although RT is suggested to negatively affect bladder function, there have been few studies of the urodynamic changes related to adjuvant RT after RH. A few studies have shown that RT may result in a decrease in cystometric capacity and poor bladder compliance (BC). Chuang and Kuo [5] demonstrated that pa-
Corresponding author: Seung-June Oh

Department of Urology, Seoul National University Hospital, 101 Daehak-ro, Jongno-gu, Seoul 110-744, Korea

Tel: +82-2-2072-2406 / Fax: +82-2-742-4665 / E-mail: sjo@snu.ac.kr

Submitted: April 26, 2012 / Accepted after revision: June 5, 2012
This is an Open Access article distributed under the terms of the Creative Commons Attribution Non-Commercial License (http://creativecommons.org/licenses/by-nc/3.0/) which permits unrestricted non-commercial use, distribution, and reproduction in any medium, provided the original work is properly cited. 
tients who were treated by RH with RT had worse bladder conditions than did patients treated by RH only. Moreover, the results of previous studies support that adjuvant RT might affect bladder function through changes in bladder histology as the result of radiation cystitis. Chan and Epstein [6] reported that RT causes epithelial proliferation and fibrin deposition in the bladder. These histologic changes might affect bladder function. Miyauchi et al. [7] showed that postoperative RT caused a significant deterioration of bladder function compared with that of an extended hysterectomy group.

However, some studies have demonstrated no clinically significant differences in the effect of RT. Lin et al. [8] reported that there were no significant differences in the results of urodynamic study between an RH only group and a combination group that underwent RH with RT. Thus, the effect of RT on bladder function after $\mathrm{RH}$ remains controversial. In the present study, therefore, we aimed to assess the urodynamic effect of RT on the urinary bladder function in patients who underwent $\mathrm{RH}$ for uterine cervical cancer to elucidate whether RT may further damage urinary bladder function.

\section{MATERIALS AND METHODS}

This study was designed as a retrospective review of the prospectively measured preoperative and postoperative urodynamic variables. All women $(n=42)$ who between May 2006 and June 2008 underwent $\mathrm{RH}$ for uterine cervical cancer with a stage of $1 \mathrm{~A}$ to $2 \mathrm{~B}$ with or without adjuvant $\mathrm{RT}$ were enrolled in this study. Exclusion criteria were the presence of diabetes mellitus, neurogenic bladder, interstitial cystitis, and history of previous pelvic surgery. All RH surgeries were performed by a single gynecologist. All patients were encouraged to void after removal of the urethral catheter on postoperative 8 days, and post-void residual (PVR) urine volume was checked. If the PVR did not decrease to less than $100 \mathrm{~mL}$ until postoperative 10 days, the patients were instructed to perform clean intermittent self-catheterization according to our previous report [9]. Patients were followed up at the urology outpatient clinic for subsequent management of urinary problems.

The patients were divided into two groups. Group 1 consisted of the patients who did not undergo RT after RH, and group 2 consisted of the patients who underwent adjuvant RT after $\mathrm{RH}$. All patients of group 2 underwent RT during the third postoperative week. RT was delivered at a dose of 1.75 to $2 \mathrm{~Gy}$ (median, $1.8 \mathrm{~Gy}$ ) per fraction once daily, 5 days per week. The median dose to the whole pelvis was $50.4 \mathrm{~Gy}$, and the median treatment time was 6 weeks [10].

Urodynamic studies (UDS) were conducted before, 10 days, and 6 months after RH. UDS were performed by the same examiners according to the same protocol (UD-2000, Medical Measurement System, Enschede, the Netherlands) throughout the study period $[6,11]$. The changes in maximal cystometric capacity (MCC) and BC among the three periods were measured. All the terms used in this study followed the definitions reported by the guidelines of the International Continence Society [12]. This study was approved by the Institutional Review Board of the Seoul National University Hospital. All values are given as means \pm standard errors (SEs). Descriptive analyses for age were performed. The urodynamic findings were compared between the two groups by use of the independent Student's ttest and analysis of covariance. All statistical analyses were performed by using commercially available software SPSS ver. 17.0 (SPSS Inc., Chicago, IL, USA) and SAS ver. 9.2 (SAS Institute Inc., Cary, NC, USA). A two-tailed P-value of 0.05 was considered to indicate statistical significance.

\section{RESULTS}

Group 1 and 2 consisted of 28 and 14 patients, respectively. The patients' mean age $( \pm$ SE) was $51.9( \pm 12.3)$ years. The preoperative clinical characteristics of the 42 patients are listed in Table 1. There were no significant differences between the two groups with regard to age, body mass index, or the International Fed-

Table 1. Patients demographics in each group

\begin{tabular}{lccc}
\hline & $\begin{array}{c}\text { Group 1 } \\
\text { (RH only) }\end{array}$ & $\begin{array}{c}\text { Group 2 } \\
(\mathrm{RH}+\mathrm{RT})\end{array}$ & P-value \\
\hline Number & 28 & 14 & \\
Age (yr) & $50.6 \pm 12.6$ & $54.6 \pm 11.6$ & $0.326^{\mathrm{a})}$ \\
Body mass index $\left(\mathrm{kg} / \mathrm{m}^{2}\right)$ & $24.4 \pm 3.9$ & $24.3 \pm 4.1$ & $0.938^{\mathrm{a})}$ \\
FIGO stage & & & $0.525^{\mathrm{b})}$ \\
1A & 1 & 0 & \\
1B & 23 & 10 & \\
2A & 1 & 2 & \\
2B & 3 & 2 & \\
\hline
\end{tabular}

Values are presented as mean \pm standard error. FIGO, the International Federation of Gynecology and Obstetrics; RH, radical hysterectomy; $\mathrm{RT}$, radiation therapy.

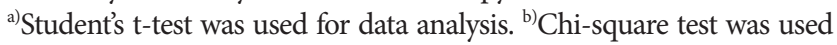
for data analysis. 
eration of Gynecology and Obstetrics stage.

The urodynamic parameters of the 42 patients preoperatively and at postoperative 10 days and 6 months are summarized in

Table 2. Changes in urodynamic parameters in total 42 patients

\begin{tabular}{lccc}
\hline & Preoperative & $\begin{array}{c}\text { Postoperative } \\
\text { tenth day }\end{array}$ & $\begin{array}{c}\text { Postoperative } \\
\text { sixth month }\end{array}$ \\
\hline Uroflowmetry & & & \\
Qmax $(\mathrm{mL} / \mathrm{sec})$ & $23.6 \pm 1.6$ & $3.9 \pm 0.8$ & $18.3 \pm 1.7$ \\
Voided volume $(\mathrm{mL})$ & $279.1 \pm 17.8$ & $50.6 \pm 13.0$ & $228.8 \pm 23.8$ \\
PVR $(\mathrm{mL})$ & $25.6 \pm 6.0$ & $171.2 \pm 16.8$ & $81.6 \pm 14.9$ \\
Cystometry & & & \\
MCC $(\mathrm{mL})$ & $416.5 \pm 12.0$ & $338.3 \pm 15.5$ & $424.1 \pm 17.0$ \\
BC $\left(\mathrm{mL} / \mathrm{cm} \mathrm{H}_{2} \mathrm{O}\right)$ & $93.6 \pm 7.2$ & $19.3 \pm 4.2$ & $71.1 \pm 9.1$ \\
First desire $(\mathrm{mL})$ & $229.2 \pm 10.6$ & $226.0 \pm 13.9$ & $253.9 \pm 16.0$ \\
Normal desire $(\mathrm{mL})$ & $320.1 \pm 14.2$ & $291.9 \pm 15.3$ & $338.4 \pm 17.5$ \\
Strong desire $(\mathrm{mL})$ & $416.5 \pm 12.0$ & $338.3 \pm 15.5$ & $424.1 \pm 17.0$ \\
Pressure-flow study & & & \\
PdetQmax $\left(\mathrm{cmH}{ }_{2} \mathrm{O}\right)$ & $33.1 \pm 1.9$ & $29.3 \pm 3.3$ & $27.7 \pm 3.1$ \\
\hline
\end{tabular}

Values are presented as mean \pm standard error.

Qmax, maximal flow rate; PVR, post-voided residual; MCC, maximal cystometric capacity; BC, bladder compliance; PdetQmax, detrusor pressure at maximum flow rate.
Table 2. At postoperative 10 days, almost all parameters except PVR showed a tendency to decrease compared with the preoperative baseline data. Compared with the respective preoperative parameters, the mean maximal flow rate was significantly decreased and PVR was significantly increased at postoperative 10 days. At postoperative day 10, MCC and BC were 338.3 $( \pm 15.5) \mathrm{mL}$ and $19.3( \pm 4.2) \mathrm{mL} / \mathrm{cmH}_{2} \mathrm{O}$, respectively. Although normal desire to void and detrusor pressure at maximum flow rate decreased slightly at postoperative 10 days, the maximal flow rate and $\mathrm{BC}$ showed a significant decrease. At 6 months, mean MCC and BC were $424.1( \pm 17.0) \mathrm{mL}$ and $71.1( \pm 9.1)$ $\mathrm{mL} / \mathrm{cmH}_{2} \mathrm{O}$, respectively.

The results of the urodynamic study of bladder function in each group are shown in Table 3 . Compared with that in group 2, BC increased significantly in group 1 at 6 months. Also, MCC at 6 months was significantly higher in group 1 than group 2 $(\mathrm{P}=0.02)$. At 6 months postoperatively, the $\mathrm{BC}$ of group 1 had increased four times or more compared with that of postoperative 10 days. However, it had increased only 2.5 times in group 2 during same period $(\mathrm{P}<0.001)$.

\section{DISCUSSION}

The incidence rate of bladder dysfunction after radical pelvic

Table 3. Changes in urodynamic parameters in each group

\begin{tabular}{|c|c|c|c|c|c|c|c|}
\hline & \multicolumn{3}{|c|}{ Group 1 (RH only, $\mathrm{n}=28)$} & \multicolumn{3}{|c|}{ Group $2(\mathrm{RH}+\mathrm{RT}, \mathrm{n}=14)$} & \multirow[b]{2}{*}{$\mathrm{P}$-value ${ }^{\mathrm{a})}$} \\
\hline & Preoperative & $\begin{array}{c}\text { Postoperative } \\
\text { tenth day }\end{array}$ & $\begin{array}{l}\text { Postoperative } \\
\text { sixth month }\end{array}$ & Preoperative & $\begin{array}{c}\text { Postoperative } \\
\text { tenth day }\end{array}$ & $\begin{array}{l}\text { Postoperative } \\
\text { sixth month }\end{array}$ & \\
\hline \multicolumn{8}{|l|}{ Uroflowmetry } \\
\hline $\mathrm{Qmax}(\mathrm{mL} / \mathrm{sec})$ & $21.7 \pm 1.2$ & $4.5 \pm 1.1$ & $18.5 \pm 1.6$ & $27.6 \pm 14.4$ & $2.6 \pm 1.1$ & $18.0 \pm 4.3$ & 0.5 \\
\hline Voided volume (mL) & $273.1 \pm 22.1$ & $64.5 \pm 18.7$ & $247.8 \pm 30.4$ & $291.1 \pm 31.1$ & $22.9 \pm 7.8$ & $190.7 \pm 36.9$ & 0.58 \\
\hline $\operatorname{PVR}(\mathrm{mL})$ & $22.5 \pm 6.3$ & $163.5 \pm 21.0$ & $86.3 \pm 20.7$ & $31.9 \pm 13.2$ & $186.5 \pm 28.3$ & $72.1 \pm 17.9$ & 0.76 \\
\hline \multicolumn{8}{|l|}{ Filling cystometry } \\
\hline $\operatorname{MCC}(\mathrm{mL})$ & $400.8 \pm 15.1$ & $336.9 \pm 18.1$ & $446.0 \pm 16.6$ & $447.9 \pm 17.5$ & $341.2 \pm 30.2$ & $380.4 \pm 36.8$ & 0.02 \\
\hline $\mathrm{BC}\left(\mathrm{mL} / \mathrm{cmH}_{2} \mathrm{O}\right)$ & $94.8 \pm 9.8$ & $22.3 \pm 6.1$ & $87.6 \pm 11.8$ & $91.2 \pm 9.6$ & $13.3 \pm 2.1$ & $38.1 \pm 9.2$ & $<0.001$ \\
\hline First desire $(\mathrm{mL})$ & $210.6 \pm 12.7$ & $218.7 \pm 16.6$ & $248.7 \pm 18.5$ & $266.5 \pm 15.5$ & $240.6 \pm 25.6$ & $264.3 \pm 31.7$ & 0.16 \\
\hline Normal desire (mL) & $297.9 \pm 18.3$ & $283.6 \pm 18.0$ & $345.8 \pm 19.3$ & $364.6 \pm 17.3$ & $308.6 \pm 29.1$ & $323.7 \pm 36.2$ & 0.66 \\
\hline Strong desire $(\mathrm{mL})$ & $400.8 \pm 15.1$ & $336.9 \pm 18.1$ & $446.0 \pm 16.6$ & $447.9 \pm 17.5$ & $341.2 \pm 30.2$ & $380.4 \pm 36.8$ & 0.02 \\
\hline \multicolumn{8}{|l|}{ Pressure-flow study } \\
\hline PdetQmax $\left(\mathrm{cmH}_{2} \mathrm{O}\right)$ & $34.3 \pm 2.3$ & $30.5 \pm 3.3$ & $28.6 \pm 3.1$ & $26.3 \pm 9.1$ & $26.3 \pm 9.1$ & $24.8 \pm 8.6$ & 0.55 \\
\hline
\end{tabular}

Values are presented as mean \pm standard error.

RH, radical hysterectomy; RT, radiation therapy; Qmax, maximal flow rate; PVR, post-voided residual; MCC, maximal cystometric capacity; BC, bladder compliance; PdetQmax, detrusor pressure at maximum flow rate.

${ }^{a)}$ Analysis of covariance was used for data analysis. 
surgery for uterine cervical cancer is known to be between $70 \%$ and $85 \%[13,14]$. A few studies have suggested that the bladder dysfunction after RH may be transient and that bladder function may recover to baseline within 6 to 12 months $[2,15]$. However, Sekido et al. [16] reported complicated postoperative urinary tract dysfunction that was sustained for more than 10 years. In general, bladder dysfunction after radical pelvic surgery is known to be related to denervation of the autonomic nerve during surgical procedures. Chen et al. [3] suggested that posthysterectomy changes in urinary tract function may be related to the partial denervation of the autonomic nerve. Our results suggested that the transient decrease in maximal bladder capacity and BC after RH with or without RT probably occurred during the immediate postoperative period. However, $\mathrm{BC}$ and maximal bladder capacity were improved to some degree after 6 months. Zullo et al. [4] suggested that the most important factor for postoperative bladder dysfunction was the resection of vaginal and paravaginal tissue.

In a previous animal study, Lundbeck et al. [17] demonstrated a dose-dependent decrease in $\mathrm{BC}$ with bladder irradiation. However, controversy exists over the clinical implications of the effect of adjuvant RT on bladder function after radical pelvic surgery. Choo et al. [18] reported changes in urodynamic parameters between baseline and 18 months after RT by analysed the patients with adenocarcinoma of the prostate. This was the first quantitative study of the effect of RT on urodynamics. Nevertheless, their results had some limitations, such as the small case series with only 17 patients and the lack of control for other factors that could affect BC and contractility, even though all the patients were old aged prostate cancer patients. Regarding uterine cervical cancer, there have been few studies in the literature about the effect of RT.

Lin et al. [8] reported that there was no significant difference in the results of urodynamic study between a RH only group and a combination group that underwent RH and RT. By contrast, Chuang and Kuo [5] reported that patients who were treated by RH with RT had worse bladder conditions. Thus, controversy remains about the effect of RT, and it is very difficult to solve this problem. From the view-point of the postoperative recovery of bladder function, in our study, group 2 showed slower improvement that did group 1 . Therefore, the results of our study support the theory that RT may result in the deterioration of postoperative bladder function.

Our study has clinical significance because few studies have assessed the effect of RT by use of urodynamic findings. Al- though our study had a small sample size and a relatively short duration of follow-up, our results were an analysis of single surgeon's surgical outcomes. Therefore, our results minimized the biases introduced by multiple surgeons and different surgical skills. In addition, our study was performed by using a centralized intensive education system for clean intermittent self-catheterization as we mentioned [9]. All our patients underwent a follow-up protocol based on strict clean intermittent self-catheterization and regular urodynamic examinations. By using urodynamic parameters, our results support that $\mathrm{RH}$ due to uterine cervical cancer causes an alteration in bladder emptying function and that this change in bladder function is probably transient. Also, our results demonstrated that adjuvant RT may be detrimental to bladder function, especially BC. This effect of RT may cause functional obstructive uropathy or urinary incontinence if the decreasing intravesical pressure is not properly managed. There are a few studies on the risk of changes to the upper urinary tract related to decreased BC $[19,20]$. Comiter et al. [19] suggested that decreased compliance alone did not have a relatively greater risk of the incidence of azotemia but found a significantly increased risk of renal insufficiency in patients with decreased compliance combined with bladder outlet obstruction.

Considering that adjuvant RT is inevitable for advanced uterine cervical cancer, our final goal for treatment should be not only the gaining of good oncologic outcomes but also the prevention of upper urinary tract deterioration secondary to decreased BC. As a result, we recommend that the upper and lower urinary tract should be monitored carefully in patients undergoing RH and adjuvant RT. Our future work will focus on the long-term follow-up of these patients and the enlargement of sample size. Additional studies are warranted.

In conclusion, $\mathrm{RH}$ gives rise to a transient alteration in the neurophysiology of the lower urinary tract. Although these changes return to normal within a certain period of time, it is highly suggested that practitioners pay attention to low BC, especially in patients who receive adjuvant RT after RH. Further studies with a larger number of patients and long-term followup are needed to explore upper urinary tract damage.

\section{CONFLICT OF INTEREST}

No potential conflict of interest relevant to this article was reported. 


\section{REFERENCES}

1. Jemal A, Siegel R, Ward E, Hao Y, Xu J, Thun MJ. Cancer statistics, 2009. CA Cancer J Clin 2009;59:225-49.

2. Chuang TY, Yu KJ, Penn IW, Chang YC, Lin PH, Tsai YA. Neurourological changes before and after radical hysterectomy in patients with cervical cancer. Acta Obstet Gynecol Scand 2003;82:954-9.

3. Chen GD, Lin LY, Wang PH, Lee HS. Urinary tract dysfunction after radical hysterectomy for cervical cancer. Gynecol Oncol 2002; 85:292-7.

4. Zullo MA, Manci N, Angioli R, Muzii L, Panici PB. Vesical dysfunctions after radical hysterectomy for cervical cancer: a critical review. Crit Rev Oncol Hematol 2003;48:287-93.

5. Chuang FC, Kuo HC. Management of lower urinary tract dysfunction after radical hysterectomy with or without radiotherapy for uterine cervical cancer. J Formos Med Assoc 2009;108:619-26.

6. Chan TY, Epstein JI. Radiation or chemotherapy cystitis with “pseudocarcinomatous" features. Am J Surg Pathol 2004;28:909-13.

7. Miyauchi T, Nagayama T, Nakada T. The late effect of hysterectomy with or without postoperative radiotherapy on bladder dysfunction in patients with uterine cancer. Int Urogynecol J 1995;6:130-7.

8. Lin HH, Sheu BC, Lo MC, Huang SC. Abnormal urodynamic findings after radical hysterectomy or pelvic irradiation for cervical cancer. Int J Gynaecol Obstet 1998;63:169-74.

9. Oh SJ, Ku JH, Lim SH, Jeon HG, Son H. Effect of a 'centralized intensive education system' for clean intermittent self-catheterization in patients with voiding dysfunction who start catheterization for the first time. Int J Urol 2006;13:905-9.

10. Kim JH, Kim HJ, Hong S, Wu HG, Ha SW. Post-hysterectomy radiotherapy in FIGO stage IB-IIB uterine cervical carcinoma. Gynecol Oncol 2005;96:407-14.
11. Cho SY, Yi JS, Oh SJ. The clinical significance of poor bladder compliance. Neurourol Urodyn 2009;28:1010-4.

12. Abrams P, Cardozo L, Fall M, Griffiths D, Rosier P, Ulmsten U, et al. The standardisation of terminology of lower urinary tract function: report from the Standardisation Sub-committee of the International Continence Society. Neurourol Urodyn 2002;21:167-78.

13. Low JA, Mauger GM, Carmichael JA. The effect of Wertheim hysterectomy upon bladder and urethral function. Am J Obstet Gynecol 1981;139:826-34.

14. Scotti RJ, Bergman A, Bhatia NN, Ostergard DR. Urodynamic changes in urethrovesical function after radical hysterectomy. Obstet Gynecol 1986;68:111-20.

15. Ralph G, Winter R, Michelitsch L, Tamussino K. Radicality of parametrial resection and dysfunction of the lower urinary tract after radical hysterectomy. Eur J Gynaecol Oncol 1991;12:27-30.

16. Sekido N, Kawai K, Akaza H. Lower urinary tract dysfunction as persistent complication of radical hysterectomy. Int J Urol 1997;4: 259-64.

17. Lundbeck F, Ulso N, Overgaard J. Cystometric evaluation of early and late irradiation damage to the mouse urinary bladder. Radiother Oncol 1989;15:383-92.

18. Choo R, Do V, Herschorn S, DeBoer G, Danjoux C, Morton G, et al. Urodynamic changes at 18 months post-therapy in patients treated with external beam radiotherapy for prostate carcinoma. Int J Radiat Oncol Biol Phys 2002;53:290-6.

19. Comiter CV, Sullivan MP, Schacterle RS, Cohen LH, Valla SV. Urodynamic risk factors for renal dysfunction in men with obstructive and nonobstructive voiding dysfunction. J Urol 1997;158:181-5.

20. Leng WW, McGuire EJ. Obstructive uropathy induced bladder dysfunction can be reversible: bladder compliance measures before and after treatment. J Urol 2003;169:563-6. 